\title{
Instabilidade macroeconômica e rigidez do spread bancário no Brasil: avaliação empírica e proposição de política*
}

\author{
Guilherme Jonas Costa da Silva* \\ José Luís da Costa Oreiro ${ }^{* *}$ \\ Luiz Fernando de Paula**
}

\section{Introdução}

Vários estudos internacionais têm destacado a importância dos fatores macroeconômicos na determinação do spread bancário, tais como a taxa de inflação, taxa de juros e sua volatilidade, PIB, capacidade utilizada, etc. No caso do Brasil, considerando a instabilidade macroeconômica que tem caracterizado a economia brasileira - expressa, por exemplo, no movimento de stop-and-go do produto e nas elevadíssimas taxas de juros - é de se esperar que tais fatores tenham uma importância significativa na explicação do spread.

A questão ganha maior relevância, ainda, ao se constatar que, apesar da queda da taxa de juros que ocorreu a partir de meados de 1999, o spread bancário no Brasil ainda se mantém em patamares elevadíssimos em termos internacionais, situando-se ao redor de $40 \%$ nos últimos anos. De fato, um dos principais fatores que impedem o crescimento do crédito no Brasil são as elevadíssimas taxas de juros dos empréstimos que têm sido praticadas no país, que explica, ao menos em parte, a alta rentabilidade dos grandes bancos varejistas. Por sua vez, o baixo nível de crédito no Brasil é um dos fatores que tem contribuído para que a economia cresça abaixo de seu nível potencial.

Nesse contexto, o presente artigo tem por objetivo aprofundar a discussão sobre a determinação do spread bancário no Brasil, procurando, em particular, analisar os determinantes macroeconômicos do spread no período recente. Para tanto, o artigo está estruturado em 6 seções, além desta introdução. Na seção 2 é realizada uma breve revisão da literatura sobre os determinantes do spread, enquanto que a seção 3 avalia alguns estudos de caso. A seção 4, por sua vez, efetua uma análise da evolução e dos determinantes do spread

\footnotetext{
* Este artigo é uma versão resumida do trabalho intitulado: "Comportamento do spread bancário no Brasil: uma avaliação empírica recente" dos mesmos autores, o qual deverá ser publicado no livro "Eficiência microeconômica e funcionalidade macroeconômica do sistema bancário brasileiro", organizado por Luiz Fernando de Paula e José Luís Oreiro.

* Doutorando em Economia pelo CEDEPLAR/UFMG e bolsista da Fundação de Amparo a Pesquisa de Minas Gerais - FAPEMIG. Endereço eletrônico: guilhermejonas@yahoo.com.br

** Doutor em Economia pelo IE/UFRJ, Professor do Departamento de Economia da UFPR e Pesquisador do CNPq. Endereço eletrônico: joreiro@ufpr.br Pagina pessoal: http://www.joseluisoreiro.ecn.br

*** Professor da Universidade do Estado do Rio de Janeiro (UERJ) e pesquisador do CNPq. Endereço eletrônico: luizfpaula@terra.com.br Página pessoal: http://paginas.terra.com.br/educacao/luizfpaula
} 
bancário no Brasil. Já na seção 5 realiza-se uma análise de regressão múltipla com o intuito de identificar as variáveis macroeconômicas que podem estar influenciando direta ou indiretamente o spread no país no período 1994-2003. A seção 6, a título de conclusão, sumariza as principais conclusões do artigo.

\section{Fundamentos Teóricos do Spread Bancário ${ }^{1}$}

A literatura teórica convencional sobre os determinantes do spread bancário tem se desenvolvido em torno de duas principais abordagens. Na primeira abordagem (modelos de monopólio), utiliza-se o trabalho seminal é Klein (1971). Na segunda abordagem, cujo trabalho seminal é Ho \& Saunders $(1981)^{2}$, o banco é visto não como uma firma, mas como um simples intermediário entre o tomador final (as firmas) e o emprestador último (as famílias). Essa atividade de intermediação está sujeita a dois tipos de incerteza: a primeira gerada pela falta de sincronização entre depósitos e empréstimos e a segunda decorrente do fato de que uma parte dos empréstimos não será devolvida em função da inadimplência voluntária (ou não) dos tomadores. O percentual de empréstimos em default, contudo, não é uma variável conhecida ex-ante pelo banco, o qual pode apenas estimar uma probabilidade de default.

Uma característica comum a ser destacada entre as abordagens de Klein e Ho \& Saunders é a suposição de que os bancos têm poder de mercado, ou seja, assumem-se em ambas as abordagens que os bancos têm liberdade para fixar o nível da taxa de juros cobrada sobre as operações de crédito e paga sobre a captação de depósitos. No entanto, ao contrário da abordagem de Klein, supõe-se que o banco é um agente avesso ao risco na abordagem de Ho \& Saunders.

Com efeito, a abordagem Ho \& Saunders é que ela abre um espaço para a influência de variáveis macroeconômicas na determinação do spread bancário (cf. Saunders \& Schumacher, 2000, p.815), notadamente, a volatilidade da taxa de juros cobrada sobre os empréstimos realizados no mercado interbancário que é reflexo direto da estabilidade macroeconômica do país. Quanto mais instável for a economia de um dado país - por exemplo, quanto maior for a variabilidade da taxa de inflação e da taxa de câmbio - maior será

\footnotetext{
${ }^{1}$ Mais detalhes das abordagens podem ser obtidos em Silva, Oreiro \& Paula (2006).

${ }^{2}$ Extensões do modelo básico de Ho \& Saunders foram feitas por Allen (1988), McChane \& Sharpe (1985), Angbazo (1997) e Maudos \& Guevara (2003). No que se segue iremos trabalhar com a extensão mais recente desenvolvida pelos últimos autores.
} 
a volatilidade resultante da taxa básica de juros ${ }^{3}$ e, por conseguinte, maior deverá ser o spread bancário ${ }^{4}$. Nesse contexto, o spread pode ser reduzido por intermédio de políticas macroeconômicas que diminuíssem a volatilidade da taxa básica de juros.

A instabilidade macroeconômica pode afetar o spread bancário por mais dois outros canais. O primeiro deles é o grau de aversão ao risco. Com efeito, a aversão ao risco dos bancos deve, em alguma medida, refletir a própria instabilidade do ambiente de mercado no qual eles operam. Quanto mais instável for esse ambiente, maior deve ser a aversão ao risco dos bancos. Sendo assim, um país que possua um histórico de grande instabilidade macroeconômica deverá possuir bancos que tenham um elevado grau de aversão ao risco.

O segundo canal é a co-variância entre o risco de taxa de juros e o risco de crédito. Uma elevada volatilidade da taxa básica de juros deve se traduzir, em alguma medida, numa alta variabilidade do nível de produção real. Nesse contexto, os lucros das firmas também deverão apresentar uma grande variabilidade, o que aumenta a probabilidade de default nos momentos em que os lucros estiverem abaixo do seu valor esperado. Daqui se segue que a instabilidade macroeconômica se reflete não apenas numa alta volatilidade da taxa de juros, como também num elevado risco de crédito, ou seja, essa instabilidade gera uma grande covariância entre o retorno dos empréstimos e o retorno das aplicações no mercado interbancário.

\section{Estudos de casos internacionais}

Nos últimos anos, uma vasta literatura empírica sobre os determinantes do spread bancário tem sido desenvolvida com intuito de testar empiricamente o modelo teórico de spread bancário desenvolvido por Ho \& Saunders (1981). Alguns dos trabalhos mais importantes nessa linha de pesquisa são McShane \& Sharpe (1985), Angbazo (1997), Saunders \& Shumacher (2000) e Maudos \& Guevara (2003).

A maior parte desses trabalhos utiliza a metodologia de estimação do "spread puro" desenvolvida pioneiramente por Ho \& Saunders ${ }^{5}$. Essa metodologia tem a vantagem de separar a influência sobre o "spread puro" das variáveis macroeconômicas (como, por

\footnotetext{
${ }^{3}$ Principalmente no caso em que a política monetária é conduzida com base no sistema de metas de inflação. $4 \mathrm{O}$ risco de taxa de juros está relacionado ao risco de um banco ter um spread pequeno ou mesmo negativo em suas operações de intermediação financeira, devido às oscilações das taxas de juros de mercado: no momento de refinanciamento do ativo pode ocorrer uma variação nos custos de captação que pode ser incompatível com o rendimento esperado das aplicações. Conseqüentemente, os lucros podem ser reduzidos, caso um banco com uma grande quantidade de ativos com taxas de juros fixas venha a se deparar com um grande aumento nos custos de captação de curto prazo.

5 Mais detalhes podem ser obtidos no trabalho de Silva, Oreiro \& Paula (2006).
} 
exemplo, a volatilidade da taxa de juros) da influência das variáveis microeconômicas (como, por exemplo, a estrutura de mercado do setor bancário).

Um trabalho empírico importante dessa literatura foi desenvolvido por Saunders \& Schumacher (2000). Os resultados obtidos foram os seguintes:

- Entre as variáveis microeconômicas, aquela que tem maior impacto sobre o spread bancário é o pagamento implícito de juros. Em outras palavras, os bancos compensam a renúncia de receita na forma de isenção de tarifas com uma maior margem de intermediação financeira. $\mathrm{O}$ requerimento de capital próprio também apresentou uma influência positiva e estatisticamente significativa sobre o spread puro.

- A estrutura de mercado do setor bancário tem pouca influência sobre os spreads. Com efeito, apenas $0,20 \%$ das margens de intermediação podem, na média, ser explicadas pelo poder de mercado dos bancos.

- A volatilidade da taxa de juros tem um impacto positivo e estatisticamente significativo sobre o spread bancário. Isso significa que quanto maior for a volatilidade da taxa básica de juros maior será, em média, o spread cobrado pelos bancos.

Uma outra linha de investigação empírica sobre os determinantes do spread bancário em nível mundial é conduzida por Demirgüç-Kunt e Huizinga (1999). Esses autores investigam os determinantes dos spreads através do uso de estatísticas bancárias desagregadas de 7900 bancos comerciais de 80 países no período 1988-1995. As variáveis independentes utilizadas refletiram as características bancárias, as condições macroeconômicas ${ }^{6}$, a taxação dos bancos, os depósitos compulsórios e a estrutura financeira geral, incluindo indicadores institucionais.

Entretanto, concluem que a taxa de crescimento do PIB real e o PIB per capita não parecem ter, em nível mundial, qualquer impacto estatisticamente significativo sobre os spreads. A inflação, medida pelo deflator implícito do PIB, tem um impacto positivo, porém estatisticamente insignificante sobre a margem líquida de intermediação dos bancos. Por fim, a taxa real de juros tem um efeito positivo e estatisticamente significativo sobre os spreads, mas esse efeito é menor nos países desenvolvidos do que nos países em desenvolvimento.

Uma análise empírica usando dados em painel sobre os determinantes do spread bancário nos países da América Latina é feita por Brock \& Rojas-Suárez (2000). Nesse estudo,

\footnotetext{
${ }^{6}$ As variáveis macroeconômicas incluem o PIB per capita, a taxa de crescimento do PIB real, a taxa de inflação e a taxa real de juros.
} 
os autores utilizam uma amostra de bancos de seis países latino-americanos (Argentina, Bolívia, Colômbia, Chile, México e Peru) no período 1992-1996. A principal conclusão deste estudo é que a influência das variáveis microeconômicas é condicional ao estado de solidez ou fragilidade dos sistemas bancários domésticos.

Outra conclusão do trabalho foi que as variáveis macroeconômicas apresentaram um impacto diferenciado de acordo com o país. Desta forma, a volatilidade da taxa de juros apresentou um impacto positivo e forte sobre o spread bancário na Bolívia e no Chile, mas um efeito negligenciável no México. A taxa de crescimento do PIB real teve um impacto negativo sobre os spreads no Chile e na Argentina, e negligenciável nos demais países. Por fim, a taxa de inflação não teve impacto estatisticamente significativo em nenhum dos países estudados.

\section{Panorama geral do spread bancário no Brasil}

O spread nas operações bancárias é definido como a diferença entre a taxa de aplicação nas operações de empréstimo e a taxa de captação de recursos pelas instituições financeiras ${ }^{7}$. O comportamento do spread no Brasil apresentou uma nítida tendência de queda até início do ano 2000, mas apresenta algumas peculiaridades. Conforme pode ser visualizado no gráfico 1, o spread médio cobrado pelos bancos brasileiros alcançou um valor máximo de 150\% ao ano no início de 1995, em função das medidas de política monetária fortemente contracionistas implementadas pelo Banco Central Brasil no período após a implementação do Plano Real ${ }^{8}$, reduzindo de forma significativa no decorrer de 1996, em função de um relaxamento das medidas de arrocho monetário e uma diminuição da desconfiança dos agentes em relação ao processo de contágio da crise mexicana, até atingir o patamar de aproximadamente $40 \%$ ao ano no início de 2000. Cabe ressaltar que ele manteve-se nesses patamares - ainda elevadíssimos - desde então, comportamento que parece estar sinalizando uma rigidez para baixo do spread bancário.

\footnotetext{
7 Ao tratarmos de spreads bancários no Brasil, estamos adotando a mesma definição do Banco Central segundo o qual "o spread bancário é definido como sendo a diferença entre a taxa de empréstimo e a taxa de captação de CDB [Certificado de Depósito Bancário]. A taxa média de CDB para o conjunto das instituições financeiras foi calculada a partir de uma média das taxas individuais ponderada pela captação líquida de cada instituição.” (Banco Central do Brasil, 2002, p.50)

8 Além da política de juros reais positivos, essas medidas incluíram inicialmente o estabelecimento de um compulsório de 100\% sobre depósitos a vista, e, a partir de dezembro de 1994, 30\% sobre depósitos a prazo e de $15 \%$ sobre qualquer operação de crédito.
} 
Gráfico 1. Evolução do spread bancário no Brasil (1994-2005)

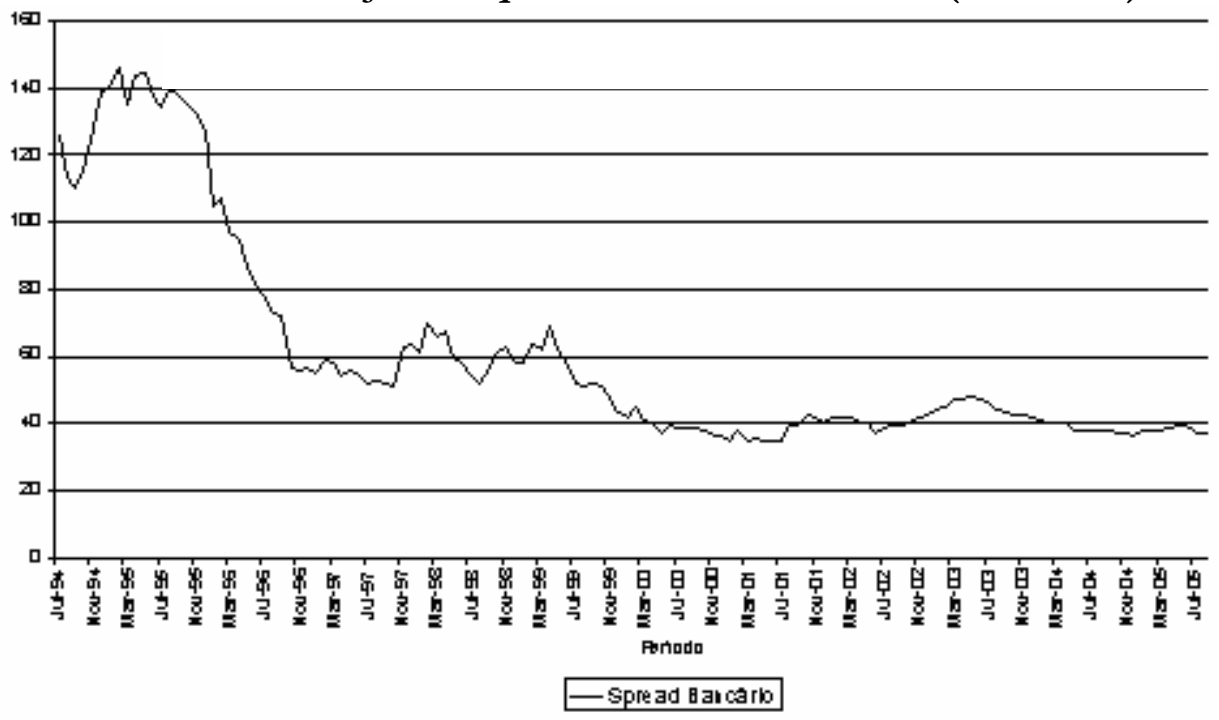

Fonte: Banco Central do Brasil

Com o sucesso do Plano Real no que se refere a estabilização de preços, poderia-se esperar um aumento substancial dos empréstimos em proporção ao PIB, já que baixas taxas de inflação sinalizariam um ambiente macroeconômico mais estável. Contudo, isso não ocorreu. Na verdade, houve uma redução do crédito como proporção do PIB $^{9}$ e constatou-se uma elevada volatilidade das taxas de juros no período, devido em grande parte aos impactos das crises financeiras internacionais em contexto de elevada vulnerabilidade externa, constituindo-se em uma fonte de instabilidade econômica. Como já assinalamos, apesar da redução em relação aos níveis de 1994, os spreads bancários permaneceram em níveis elevados nos últimos anos.

Uma primeira hipótese explicativa para o porquê dos elevados spreads praticados no Brasil seria o poder de mercado dos bancos, evidenciado pelo aumento da concentração bancário no período recente. Com efeito, alguns estudos recentes sobre o setor bancário brasileiro - como, por exemplo, Belaisch (2003) - mostram que a estrutura de mercado prevalecente nesse setor é essencialmente não-competitiva ${ }^{10}$. Nesse contexto, os bancos teriam poucos incentivos para aumentar a sua eficiência operacional, operando com spreads elevados quer como forma de gerar receita suficiente para cobrir os seus custos elevados, quer como

\footnotetext{
${ }^{9}$ Conforme dados do Banco Central do Brasil, a relação crédito total/PIB, que era de 40\% em junho de 1995, passou a ser menor do que $30 \%$ em praticamente todo o período 2000/03.

${ }^{10}$ Nakane (2002), usando séries temporais agregadas durante o período 1994-1998, encontrou evidências de existência de uma estrutura de mercado não-competitiva no setor bancário brasileiro. Entretanto, os resultados alcançados rejeitam a hipótese de que os bancos brasileiros formam um cartel.
} 
resultado da capacidade de "precificar" os seus serviços num patamar bastante superior ao custo marginal de produção dos serviços bancários.

A literatura brasileira que trata dos determinantes do spread bancário não tem sido conclusiva a respeito do assunto. Os estudos realizados apresentam evidências de que a estrutura de mercado do setor bancário brasileira é imperfeita, mas não pode ser caracterizada por nenhuma estrutura de mercado extrema (concorrência perfeita e cartel) ${ }^{11}$.

No Brasil, um dos estudos pioneiros sobre os determinantes do spread bancário no Brasil foi feito por Aronovich (1994). Este autor verificou, através de uma regressão por mínimos quadrados em dois estágios, os efeitos da inflação e do nível de atividade sobre o spread para a economia brasileira entre o primeiro trimestre de 1986 e o quarto trimestre de 1992. Os resultados encontrados indicam que a inflação tende a ampliar a diferença entre as taxas de juros de empréstimo e de captação, ou seja, o spread. $\mathrm{O}$ autor sugere como causas desse fenômeno a possibilidade de uma redistribuição entre as operações do ativo, ou ainda, a incorporação ao mark-up do prêmio de risco envolvido no crédito. Dessa forma, a inflação teria um efeito negativo sobre o nível de atividade ao induzir um aumento das taxas de juros para empréstimos bancários. Por outro lado, os testes estatísticos sugerem que um aumento da utilização de capacidade produtiva reduziria o spread, indicando assim um efeito pró-cíclico.

Neste sentido, Afanasieff et al (2002), utilizando a abordagem de dois passos de Ho \& Saunders (1981), investigaram se os fatores macro e microeconômicos são relevantes para explicar o comportamento do spread no país, e concluíram que os resultados sugerem que variáveis macroeconômicas - como a taxa básica de juros e o crescimento do produto - são os fatores mais relevantes para explicar tal comportamento. Esse resultado, contudo, não é surpreendente, considerando que outros estudos internacionais apresentam evidências de que a incerteza do ambiente econômico que envolve os bancos parece ser uma importante causa dos spreads bancários (Saunders \& Schumacher, 2000; Brock \& Suarez, 2000).

\footnotetext{
${ }^{11}$ Cabe destacar que "em princípio não existe uma relação um para um entre concentração de mercado e grau de competição [no mercado bancário] e que "algumas das mesmas forças que promovem a consolidação em países emergentes, tais como a entrada maior de bancos estrangeiros, são também aquelas que estimulam a competição". (IMF 2001, p. 158).
} 


\section{Determinantes macroeconômicos do spread bancário no Brasil: evidências empíricas}

Com intuito de apreender os principais determinantes macroeconômicos do spread bancário, estimou-se um Vetor Auto-Regressivo (doravante VAR), no qual uma variável é definida como sendo função de seus próprios valores defasados e de defasagens das demais variáveis consideradas na análise. A escolha dessas variáveis baseou-se, em larga medida, nos resultados obtidos por Afanasieff et al (2002), no qual conclui que as variáveis macroeconômicas são mais relevantes na determinação do spread do que as variáveis microeconômicas. Isto posto, o objetivo desse tópico é encontrar os determinantes macroeconômicos do spread bancário no Brasil. Acredita-se que o spread é determinado, entre outras variáveis, pela produção industrial, pela taxa de inflação, pela taxa de câmbio e pela taxa básica de juros (efeito da taxa média de juros) ${ }^{12}$.

Para a aplicação empírica, verificou-se através do teste de Dickey-Fuller Aumentado $(\mathrm{ADF})$, da análise gráfica e do diagrama da função de auto-correlação a hipótese de estacionariedade das séries econômicas. Contudo, percebeu-se que nenhuma das variáveis consideradas foi estacionária em nível ${ }^{13}$. Assim, após verificar a ordem de integração das variáveis, realizou-se o teste de cointegração de Johansen, com tendência determinística linear nos dados, com intercepto e sem tendência na equação de co-integração ${ }^{14}$. Apesar de existir uma relação de longo prazo entre as variáveis, alguns desequilíbrios de curto prazo podem ocorrer. Nesse caso, deve-se estimar um modelo com correção de erros. As estatísticas traço $\left(L R_{\text {trace }}\right)$ e máximo autovalor $\left(L R_{\max }\right)$ apontaram a presença de um vetor de co-integração, indicando a necessidade de incorporar um vetor de correção de erro.

Para desenvolver um modelo bem especificado é necessário, entre outras coisas, a escolha adequada do número de defasagens para fazer as estimações. Para tanto, toma-se

\footnotetext{
12 As variáveis selecionadas forma: i) Spread bancário, segundo o Banco Central (definido como a série 3955 spread médio das operações de crédito com recursos livres 'prefixado' - total geral); ii) Produto Industrial Brasileiro (PIB) do IBGE utilizado como uma proxy para o nível de atividade econômica (definido como a tabela 2295 do IBGE: Produção Física Industrial por tipo de índice e seções e atividades industriais); iii) Taxa de juros SELIC do Banco Central (definida como a série 4189: taxa de juros Selic acumulada no mês anualizada); iv) Taxa de inflação medida a partir da variação mensal do IPCA do IBGE (definida como a série 433 do banco central: Índice Nacional de Preços ao Consumidor-Amplo); v) Taxa de câmbio - R \$ US\$ - comercial - compra - média (extraída do IPEADATA)

13 Apesar do teste ADF ter sinalizado que as séries IPCA, SPREAD e JUROS são estacionários, a análise gráfica e principalmente do correlograma apontaram na direção oposta, por isso não foram consideradas estacionárias em nível.

${ }^{14}$ Essa especificação parece ser a mais apropriada para as series macroeconômicas analisadas nesse trabalho.
} 
como base no Critério de Informação de Schwarz (SC). O resultado observado sinalizou que o número de defasagens a incluir no VAR é um ${ }^{15}$.

Segundo Mendonça (2005), considerando que os erros são ortogonalizados pela decomposição de Cholesky para a estimação do VEC, isto implica que o ordenamento das variáveis torna-se relevante para a análise da função impulso-resposta e da decomposição da variância. Para tanto, utilizou-se o teste de precedência temporal de Granger (1969). De acordo com esse critério, a ordenação adequada é a seguinte: GIPCA, GCÂMBIO, GJUROS, GPIB e GSPREAD. Assim, a taxa de variação do spread bancário (variável de interesse nesse estudo) é a mais endógena, respondendo contemporaneamente as variações do produto, da taxa de inflação, da taxa de câmbio e da taxa de juros.

Para analisar os resultados do modelo VAR (restrito ou irrestrito) é comum fazê-lo por meio da função de impulso resposta e da decomposição da variância. Dada a freqüência mensal dos dados utiliza-se para as análises um período de 12 meses após a ocorrência dos choques. A função de impulso resposta é utilizada para fazer uma análise da sensibilidade de determinadas variáveis a certos choques, sendo útil principalmente para conhecer o tempo, a direção, o padrão de reação das respostas aos impulsos (choque) de um desvio padrão sobre os valores contemporâneos e futuros das variáveis endógenas do sistema.

Isso posto, as respostas do sistema aos choques estão apresentadas no gráfico 3. O primeiro gráfico mostra que o efeito de um choque no crescimento da inflação sobre o crescimento do spread bancário tende a provocar uma elevação persistente. Este resultado está em consonância com o resultado obtido por Aronovich (1994), o qual já havia mostrado que elevações da taxa de inflação estão associadas com um aumento do mark-up do setor bancário. O gráfico seguinte apresenta o efeito de um choque no crescimento do câmbio sobre o crescimento spread bancário, que também foi positivo ainda que pouco significante. No último gráfico da $1^{a}$ linha encontra-se o efeito de um choque no crescimento da taxa média de juros sobre o crescimento do spread que foi positivo e, pode ser considerado o choque que teve o maior impacto sobre o crescimento do spread bancário.

Este resultado confirma a hipótese de preferência pela liquidez. dos bancos (cf. Paula e Alves Jr, 2003), segundo a qual os bancos no Brasil - face a existência de uma aplicação livre de risco que combina liquidez e rentabilidade, como no caso de títulos públicos indexados passam a incorporar um elevado prêmio de liquidez nas operações de concessão de

\footnotetext{
${ }^{15}$ A análise do número de defasagens se baseou no Critério de Schwarz e na análise da ausência de correlação serial.
} 
empréstimos. Acrescente-se que, como assinalado na seção 2, elevações nas taxas de juros básica podem ocasionar uma maior variabilidade no nível da produção real e na lucratividade das firmas, elevando o risco de crédito, no que pode resultar em taxas de empréstimos e spreads maiores.

Antes de explicar o resultado do gráfico seguinte, é interessante destacar que o impacto negativo do PIB sobre o spread bancário pode ser atribuído ao "efeito inadimplência", no sentido de que um maior (menor) crescimento do produto e da renda nacional resulta em uma diminuição (aumento) na inadimplência bancária (e no risco do crédito) que tende a acarretar uma redução (aumento) no spread, enquanto o impacto positivo sobre o crescimento do spread se deve provavelmente ao efeito "poder de mercado" dos bancos. Nesse último caso, os bancos, em uma conjuntura de aumento na demanda por crédito, podem responder a este estímulo elevando a taxa de empréstimos e mantendo a taxa de depósitos inalterada.

\section{Gráfico 3. Função resposta do crescimento do spread a um impulso no crescimento das variáveis macroeconômicas}

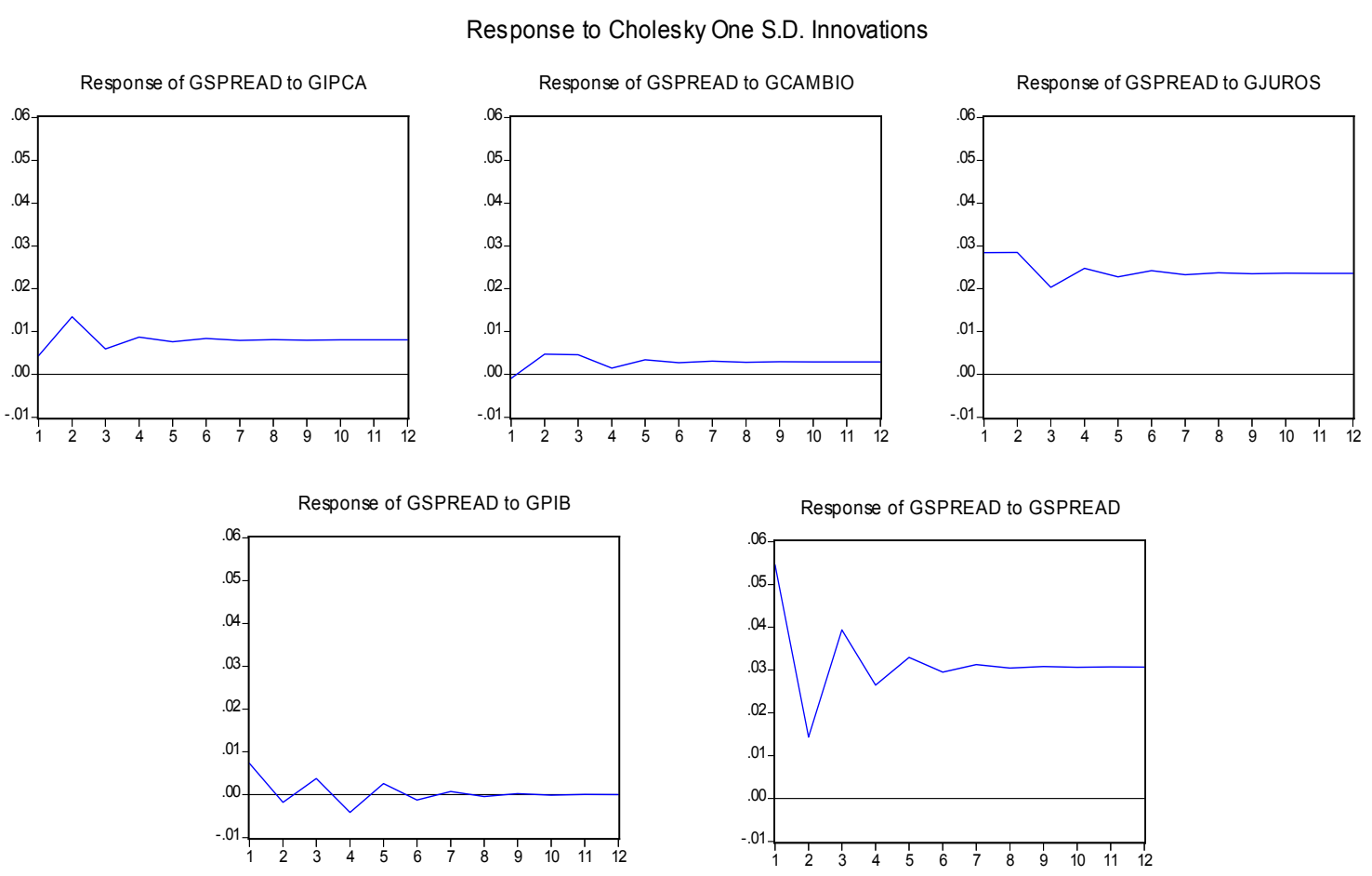

Fonte: Elaborado pelos autores

Isto posto, observe no primeiro gráfico da segunda linha que um choque na taxa de crescimento do PIB causa um efeito oscilante convergente sobre a taxa de crescimento do spread bancário. O segundo gráfico da segunda linha mostra o impacto que um choque positivo do spread bancário tende a provocar na própria variável. Podemos observar que o 
spread, tal como outras variáveis econômicas, possuem um forte componente inercial, o que fica demonstrado pelo fato de que choques nesse variável (ou na sua taxa de crescimento) no tempo $t$ têm efeito sobre os valores dessa variável em períodos subseqüentes.

A Tabela 4 apresenta a decomposição da variância, que tem por objetivo mostrar a importância de uma determinada variável quando se observa o erro de previsão de uma outra variável. Os resultados foram obtidos a partir de uma simulação de Monte Carlo com 1000 repetições. Note que o crescimento na taxa de inflação respondeu por aproximadamente 4\% da variância do crescimento do spread bancário. Os resultados mostraram que o crescimento da taxa de juros é a variável mais relevante, pois tem uma importância grande sobre a variância do crescimento do spread bancário, ou seja, cerca de 33\%. No tocante a importância do crescimento do spread bancário na explicação dele mesmo, constatou-se que representa aproximadamente $61 \%$, confirmando a hipótese de haver um forte componente inercial. A importância relativa das demais variáveis sobre o crescimento do spread é desprezível.

Tabela 4. Decomposição da Variância (\%) - Taxa de Variação do spread bancário

\begin{tabular}{cccccc}
\hline Período & GIPCA & GCÂMBIO & GJUROS & GPIB & GSPREAD \\
\hline 1 & 0.490944 & 0.023440 & 20.94865 & 1.377739 & 77.15923 \\
2 & 3.956152 & 0.464427 & 31.87199 & 1.109975 & 62.59746 \\
3 & 3.324432 & 0.627901 & 28.57153 & 0.996260 & 66.47988 \\
4 & 3.658873 & 0.549939 & 31.05942 & 1.033745 & 63.69802 \\
5 & 3.625943 & 0.573453 & 31.02841 & 0.928944 & 63.84325 \\
6 & 3.748606 & 0.561272 & 31.95413 & 0.820816 & 62.91518 \\
7 & 3.773342 & 0.565717 & 32.20051 & 0.727486 & 62.73295 \\
8 & 3.820436 & 0.560330 & 32.59733 & 0.652313 & 62.36959 \\
9 & 3.846327 & 0.559770 & 32.83500 & 0.590334 & 62.16857 \\
10 & 3.874389 & 0.558033 & 33.06895 & 0.538990 & 61.95964 \\
11 & 3.894406 & 0.557093 & 33.24848 & 0.495813 & 61.80421 \\
12 & 3.913239 & 0.556036 & 33.40838 & 0.459029 & 61.66331 \\
\hline
\end{tabular}

Fonte: elaboração própria a partir da saída do Eviews 5.

Nota: Ordem Cholesky GIPCA, GCÂMBIO, GJUROS, GPIB e GSPREAD

Em suma, as evidências recentes parecem indicar que a taxa básica de juros é a variável mais relevante na explicação do crescimento do spread bancário no Brasil. Adicionalmente, constatou-se que a taxa de inflação tem um efeito positivo sobre o crescimento do spread bancário, resultado que está associado com um aumento do mark-up do setor bancário, mas atualmente não pode ser considerado um dos principais determinantes do elevado spread bancário no país. No que tange as demais variáveis, crescimento da taxa de câmbio e da produção industrial, não há evidências concretas (no período considerado) de que são relevantes na determinação do spread bancário cobrado no país. 


\section{Conclusão}

Os resultados obtidos neste artigo evidenciaram - em consonância com a literatura internacional empírica - que os fatores macroeconômicos são importantes no Brasil na explicação da determinação do spread bancário. Em particular, destacam-se: (i) o nível da taxa de juros, que serve tanto como piso para as taxas de empréstimos como "custo de oportunidade" para as operações de empréstimos, em função da indexação a Selic de parte da dívida pública; (ii) em menor grau, a taxa de inflação, uma vez que elevações da taxa de inflação estão associadas com um aumento do mark-up do setor bancário.

Em suma, para fins de propostas de políticas para redução do spread bancário no Brasil, os resultados deste trabalho parecem indicar que a redução na taxa Selic é condição sine qua non para que se possa obter uma diminuição mais pronunciada e duradoura no spread no país.

\section{Referências bibliográficas}

AFANASIEFF, T. S., LHACER, P. M. e NAKANE, M. I. (2002) "The determinants of bank interest spread in Brazil". Money Affairs, vol. XV, n. 2, pp.183-207

ALLEN, L. (1988). "The determinants of bank interest margins: a note". Journal of Financial and Quantitative Analysis, vol. 23, pp. 231-235.

ANGBAZO, L. (1997) "Commercial bank net interest margins, default risk, interest-rate risk, and off-balance sheet banking", Journal of Banking and Finance, vol. 21, pp. 55-87.

ARONOVICH, S. (1994). "Uma nota sobre os efeitos da inflação e do nível de atividade sobre o spread bancário". Revista Brasileira de Economia, vol. 48, n. 1.

BANCO CENTRAL DO BRASIL - BCB (2004). Disponível na Internet: [http://www.bcb.gov.br]. Acesso em: 11/05/2004.

BELAISCH, A. (2003). “Do brazilian banks compete?”. IMF Working Paper, WP/03/113.

BROCK, P. L. \& SUAREZ, L.R. (2001). "Understanding the behavior of bank spreads in Latin America". Journal of Development Economics, vol. 63, pp. 113-134.

COUTINHO, R. (2003). Spread e concentração bancária no Brasil. Monografia de conclusão do curso de Ciências Econômicas. Curitiba: CSA/UFPR.

DEMIRGUC-KUNT, A. \& HUIZINGA, H. (1999). "Determinants of commercial bank interest margins and profitability: some international evidence". The World Bank Economic Review, vol. 13, n. 2, pp. 379-408.

ENDERS, W. (1995). Applied Econometric Times Series. New York: John Wiley \& Sons, Inc., $2^{\mathrm{a}}$ edição.

FREIXAS,X. \& ROCHET, J. (1999). Economía Bancaria. Antoní Bosch: Barcelona.

GRANGER, C. W. J. (1969). "Investigating causal relations by econometric models and cross-spectral methods". Econometrica, vol. 37, pp. 424-438 
HO, T. S. Y. \& SAUNDERS, A. (1981). "The determinants of bank interest margins: theory and empirical evidence". Journal of Financial and Quantitative Analysis, vol. 16, pp. 581-600.

IMF - INTERNATIONAL MONETARY FUND (2001). International Capital Markets: Developments, Prospects, and Key Policy Issues. Washington: IMF.

KLEIN, M.A. (1971). "A Theory of the Banking Firm". Journal of Money, Credit and Banking, vol. 3, n 2, pp. 205-218.

KOYAMA, S. M. \& NAKANE, M. I. (2001) "Os determinantes do spread bancário no Brasil”. In Banco Central do Brasil, Juros e Spread Bancário no Brasil: Avaliação de 2 Anos do Projeto, pp. 27-30. Brasília: Banco Central do Brasil.

MATSUMOTO, K. (2000). Efeitos reais da transmissão de política monetária: Comparação empírica entre Brasil e Argentina. Dissertação de Mestrado. FGV-RJ.

MAUDOS, J. e GUEVARA, J. F. (2004). "Factors explaining the interest margin in the banking sectors of the European Union". Journal of Banking and Finance, vol. 28, n. 9, pp. 2259-2281.

McSHANE, R.W. e SHARPE I.G. (1985). "A time series/cross section analysis of the determinants of Australian trading bank loan/deposit interest margins: 1962-1981”. Journal of Banking and Finance, vol. 9, pp.115-136.

MENDONÇA, H. F. (2005) Metas para inflação e variáveis macroeconômicas: uma avaliação empírica. Disponível em: [www.anpec.org.br/encontro2005/artigos/A05A040.pdf]. Acesso em: 01/08/2006.

NAKANE, M. I. (2003) “Concorrência e spread bancário: uma revisão da evidência para o Brasil". In: Banco Central do Brasil, Juros e Spread Bancário no Brasil: Avaliação de 4 Anos do Projeto, pp. 58-67. Brasília: Banco Central do Brasil.

NAKANE, M.I. (2002). "A test of competition in Brazilian banking”. Estudos Econômicos, n. 32, pp. 203-224.

NAKANE, M.I. e COSTA, A.C.A. (2005). "Spread bancário: os problemas da comparação internacional". Risk Update, Ano 1, n. 3, pp. 9-14.

PAULA, L.F. e ALVES JR, A.J. (2003) "Banking behaviour and the Brazilian economy after the Real Plan: a post-Keynesian approach". Banca Nazionale Del Lavoro Quaterly Review, n. 227, pp. 337-365.

RAMASWAMY, R \& SLØK, T(1998) The real effects of monetary policy in the European union: what are the differences? IMF Staff Papers, vol. 45, n. 2.

SAUNDERS, A. \& SCHUMACHER, L. (2000). "The determinants of bank interest rate margins: an international study". Journal of International Money and Finance, vol. 19, pp. 813-832.

SILVA, G. J. C.; OREIRO, J. L. \& PAULA, L. F. R. (2006). Comportamento do spread bancário no Brasil: uma avaliação empírica recente. (no prelo)

SIMS, C.(1980). "Macroeconomics and reality". Econometrica, vol. 48, n.1, pp. 1-48. 
